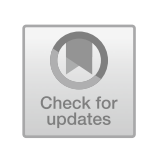

CHAPTER 6

\title{
Discussion and Conclusion
}

Abstract This chapter discusses the study findings in light of relevant theory on policy transfer and multi-level governance. Three theoretical conclusions are made: (1) public health policies today are often subject to a policy transfer 'web', in which networks of actors involving both policymakers and non-governmental organisations (NGOs) are required to navigate various different jurisdictions and levels of governance in order to ensure that a policy is successfully adopted; (2) transnational corporations have analytically-significant consequences for policy transfer processes and may act intentionally to disrupt such processes; and (3) the activities of transnational corporate actors can shape subsequent transfer processes, as policy-makers and NGOs build relationships and coalitions in an effort to adapt to, and counteract, global corporate political strategies.

Keywords Policy transfer - Multi-level governance $\cdot$ Transnational tobacco companies $\cdot$ Standardised packaging $\cdot$ Plain packaging $\cdot$ EU Tobacco Products Directive

This volume has sought to examine the development of standardised packaging (SP) policy in Europe at both the European Union (EU) and member-state levels, placing developments in Europe within the global context of tobacco-control debates and processes. As the analysis above

(C) The Author(s) 2020

B. Hawkins et al., The Battle for Standardised Cigarette Packaging in Europe, Palgrave Studies in Public Health Policy Research, https://doi.org/10.1007/978-3-030-31034-9_6 
demonstrates, SP has endured a difficult and contentious journey from policy idea through to implementation, and at the time of writing the battle is far from over. The story of the development of the policy, and the actors that have worked for its implementation, demonstrates the complex political environment that public health advocates must navigate within the EU's system of multi-level governance (MLG). Through a case study of Ireland, and employing the concepts of policy transfer and policy learning, this volume has demonstrated the regional and global significance of national policy debates, and the interconnections between policy debates in different policy-making jurisdictions. This chapter relates the empirical analysis presented in Chapters 3-5 to the literature on MLG and policy transfer presented in Chapter 2. It seeks to explain tobacco industry strategy in opposing SP in Europe, to prevent policy 'contagion' across different policy-making jurisdictions and at different levels of governance, and the responses of policy-makers and non-governmental organisations (NGOs) to this corporate activity.

The chapter is structured as follows. The following section discusses the key role of Australia as a policy innovator on SP and its implications for policy development in Europe and beyond. The Australian case demonstrates the understanding which transnational tobacco companies (TTCs) had of the potential for policy transfer to other jurisdictions, were SP to be successfully adopted there, and the vehemence with which they therefore sought to oppose the policy. The second section explores the theoretical implications of the battle over the packaging requirements included within the 2014 EU Tobacco Products Directive (TPD), as the TTCs attempted to disrupt the potential of the EU to become a 'massive transfer platform' (Radaelli 2000). The third section looks at the subsequent policy battle in Ireland. It examines the interconnections between policy debates and policy actors in Ireland, Australia and the UK in light of the policy transfer literature, and how TTCs' tactics affected those relationships. The final section elaborates three theoretical conclusions which contribute to our understanding of policy transfer: (1) public health policies today are often subject to a policy transfer 'web', in which networks of actors, including both policy-makers and NGOs, are required to navigate different levels of governance and jurisdictions in order to ensure that a policy is successfully adopted; (2) transnational corporations have analytically-significant consequences for policy transfer processes and may act intentionally to disrupt such processes; and (3) the activities of transnational corporate actors can shape subsequent policy transfer processes, as policy-makers and NGOs 
build relationships and coalitions in an effort to counteract corporate political strategies designed to prevent the adoption of public policies that run counter to their narrow corporate interests.

\section{Australia as Policy Leader}

As the first country in the world to adopt SP, Australia was subject to a barrage of well-coordinated activities by TTCs in an attempt to overturn the policy. This activity is consistent with other studies of TTC political behaviour, which demonstrate continuing aggressive political behaviour by TTCs over a number of decades (Hurt et al. 2009; Holden and Lee 2009; Smith et al. 2013; Savell et al. 2014). Previous studies have shown that TTCs were concerned not only with the impact of SP on sales in any particular jurisdiction, but with the potential for the policy idea to spread to other jurisdictions and become more widely adopted (Jarman 2015; Hawkins et al. 2018). Corporate actors are somewhat neglected in the policy transfer literature, with theoretical insights focused predominantly on the activities of policy-makers and advocates (see Chapter 2). However, the analysis presented above demonstrates that transnational corporations can be important actors within policy transfer processes, seeking to disrupt and prevent the diffusion of policy ideas and block successful transfer. Their substantial economic resources mean they are formidable opponents for both governments and NGOs seeking to implement or advocate for policy measures in the public interest.

As Australia sought to implement SP, TTCs initiated highly sophisticated, globally-coordinated political strategies to oppose the policy, which included lobbying and policy-influencing strategies, the use of third parties and multiple, concurrent legal challenges under different bodies of law (including the Australian constitution, the Australia-Hong Kong Bilateral Investment Treaty [BIT] and World Trade Organization [WTO] law) in an attempt to prevent or delay the introduction of SP (Hawkins and Holden 2016; Hawkins et al. 2018). The strength of their response to the introduction of SP at the state level suggests that their concerns went beyond the economic impact that the legislation could have on the Australian market alone. Rather, they demonstrated a significant concern that the implementation of SP in Australia could establish the principle that this was an effective form of policy intervention, compatible with international trade law and other commitments, and could trigger 'policy contagion' to 
other policy contexts, including their most important and profitable markets. Preventing policy transfer was therefore a key objective of TTCs in Australia. Due to their economic and political power, corporate actors can shape, delay and potentially prevent the implementation of a policy that they consider to be against their interests. Consequently, they should be an important analytical focus within policy transfer scholarship, and are underrepresented in the existing literature.

While Australia was targeted by the TTCs as the first state-level jurisdiction to implement SP, it was nevertheless a relatively small and declining tobacco market. The introduction of SP in the much larger EU market represented a significantly greater economic threat to the tobacco industry, given its population of over 500 million high-income consumers, highly evolved supranational governance structures that maintain coercive and normative power, and policy networks that could accelerate policy transfer. Moreover, the potential for policy adoption at the EU level and at the member-state level meant there were multiple potential routes through which policy transfer could occur, with the likelihood that adoption in one member state, if deemed compatible with EU law, would rapidly spread to others.

\section{Strengthened Packaging Requirements in the EU: The Tobacco Products Directive}

Studies of TTCs' attempts to oppose SP in Australia underline the way in which they implemented a multi-level strategy to challenge SP simultaneously on multiple fronts and at different levels of governance (Chapman and Freeman 2014; Hawkins and Holden 2016; Hawkins et al. 2018). These revealed the importance of 'venue-shifting' to direct policy decisions to those contexts in which a favourable outcome for the industry was most likely. Whilst in the Australian case this involved national law, as well as bilateral and global-level regimes, the existence of the EU as a strong regional institution added a further layer of complexity to policy-making in Europe. The EU represented a double-edged sword for TTCs. The capacity of the EU to introduce effective and enforceable tobacco-control measures under the auspices of single-market law represented an additional mechanism through which SP (or other packaging requirements) could be introduced across the twenty-eight member states, and thus posed an additional threat to tobacco companies. Even where collective action at the EU level could be avoided (as was the case with SP in the TPD), the close political 
ties and high levels of policy coordination that exist between EU member states meant that once a policy idea such as SP came onto the agenda in one member state, it had the potential to spread rapidly to others. The EU's role as a 'massive transfer platform' (Radaelli 2000) and a 'supranational idea hopper' (Bomberg and Peterson 2000) could significantly speed up policy contagion. At the same time, the highly developed legal structures within the EU, and the emphasis afforded to 'market-making' functions within its treaties, provided a further avenue through which SP at the EU level and within member states could be challenged (Holden and Hawkins 2017).

Given the size of the market, and the potential for the policy to be implemented at once across the twenty-eight member states, the EU was a key battleground for TTCs in the fight against SP. The timing of the TPD revision had both positive and negative aspects for the TTCs. Working to their disadvantage was the fact that the rotating Presidency of the Council was held by Ireland in the first semester of 2013-a key stage in the conclusion of the TPD. The Irish Government and Health Minister James Reilly held a strong political commitment to the successful conclusion of the TPD negotiations.

However, there were several structural factors within the EU institutional architecture that worked in the TTCs' favour. The political timetables in the EU, the European Parliament election scheduled for early 2014 , and the subsequent appointment of a new Commission, meant that delaying the TPD—a key aspect of the industry's strategy—could result in the legislation failing to pass before the dissolution of Parliament, necessitating the reintroduction of the TPD by a new Commission and its approval by a newly constituted European Parliament (EP) which might have a very different political outlook and set of priorities. Moreover, the governments of Lithuania (second semester 2013) and Greece (first semester 2014), who would succeed Ireland in the Council Presidency, were considered to have weaker positions on tobacco control and consequently, advocates feared, may not have had the political determination to conclude agreement on such a controversial portfolio. The complex institutional structure of the EU provided further advantages for TTCs, as the conflicting mandates and priorities of different policy actors provided opportunities to play interests off against each other. This approach has been identified in other policy areas, including studies of environmental policy making in the EU (e.g. Jordan et al. 2003). 
The analysis presented in this volume demonstrates that the TTCs developed a sophisticated, coordinated strategy that sought to exploit these advantages and stymie development of the TPD at every step of the policymaking process. TTCs employed evolving strategies at the various different stages of the policy process and via multiple points of access, demonstrating their ability to exploit the complexities of the EU's institutional architecture and disrupt the progression of policies through several different approaches. They lobbied every institution within the EU legislative process - the Commission, the Council and the Parliament - and initiated legal challenges to the TPD under EU law once it had been adopted.

In the policy development stage they targeted the Commission, seeking to undermine the leading Directorate General (DG) on the TPD, DG SANCO, by attempting to venue-shift to other DGs that were more favourable to their agenda and to challenge the narrative being developed in DG SANCO. Reflecting Baumgartner and Jones' (1991) analysis that venue-shifting requires changing the 'policy image', TTCs attempted to reframe the debate in economic terms, with a specific focus on jobs and taxes; important considerations for member states that had economic interests associated with the tobacco industry (cigarette production, packaging manufacture, etc.), and therefore a powerful counter-narrative to the considerations about public health underpinning SP. The flooding of the interservices consultation with responses and attempts to use committees other than ENVI to influence the TPD in the EP, demonstrate further the TTCs' intricate understanding of EU policy processes.

TTCs' efforts at agenda setting were partially successful. They appear to have prevented the adoption of SP at the EU level early in the Commission's processes and managed to ensure that the minimum requirements for packaging were significantly watered down (Costa et al. 2014; Peeters et al. 2015). In short, despite the stipulation in Article 5.3 of the Framework Convention on Tobacco Control (FCTC) that governments should take measures to protect health policy from 'commercial and other vested interests of the tobacco industry' (WHO 2003), the TTCs had successfully disrupted the potential of the EU to disperse SP throughout Europe (see Radaelli 2000). This demonstrates the point that changes in ideas alone are insufficient as an explanatory theory of policy change. Despite the idea of SP spreading from Australia to Europe, this was not enough to ensure the adoption of SP at the EU level. Rather, institutional structures, political processes, vested interests, competing policy priorities and relationships between actors are of vital importance in explaining policy change or stasis. 
Of particular importance is the presence of coercion and the power relationships between key policy actors. As Dobbin et al. (2007) point out, coercion theory focuses most obviously on mechanisms of policy control, such as conditionality, emanating from organisations such as the World Bank or the International Monetary Fund (IMF). However, political scientists, such as Stone (2007) and Gleditsch and Ward (2006), also argue that policy leadership and hegemonic ideas can be 'soft' forms of coercion. These theories are united by a focus on the impact of influences or ideas from external sources on the policy-making process. In this instance, the TTCs challenged the EU's normative power, pursuing a strategy to promote a counter-idea around economic and jobs considerations, which had the potential to weaken the power of the idea of SP.

The development of the TPD was not an outright victory for the TTCs, however. Although SP did not become part of the TPD, and the labelling requirements that were finally adopted were significantly watered down from the original proposals, these represented a significant advance on the previous minimum packaging requirements. Moreover, by including an explicit recognition that member states could proceed with SP at the national level, the TPD offered both a clear normative endorsement of these measures for governments and potential cover from subsequent legal challenges by the tobacco industry. This provided an important legal 'springboard' for policy action by Ireland and other member states.

\section{IRELAND}

By the time the TPD was adopted, measures to implement SP in Ireland were already in train. Ireland had been long recognised as a leader in the area of tobacco control both within Europe and globally. Despite the political commitment for SP evident in Ireland, however, the government and public health advocates faced a significant challenge in implementing the policy from TTCs opposed to its introduction. The transfer of the policy idea of SP from Australia to Ireland was only the first stage in a protracted political and legal battle for its realisation. This had to be supplemented by significant cooperation and policy learning between NGOs and advocates in Ireland and Australia, with the former drawing on the experience of, and employing the strategies developed by, those in the latter to secure the policy's successful adoption and implementation. 


\section{Policy Learning Across Jurisdictions}

Irish public health advocates turned to those in Australia for guidance on how to manage the policy-making process. Irish actors sought guidance from Australian colleagues on how to get SP successfully through the legislative process and into implementation. Central to this process was the role played by transnational NGO networks engaged in what we have termed here horizontal-consecutive policy learning. This builds on Evans and Davies' (1999) model of policy transfer, which traces the linear progression of a policy from 'exporter' to 'importer' jurisdictions. They draw on the literature on policy networks and epistemic communities to analyse how policy-makers 'acquire and utilize knowledge' (Evans and Davies 1999, 376; see Chapter 2). In the case of SP, the 'information feeder network' and 'transfer network' were not only the Australian policy-makers who contributed to the successful implementation of the policy there, but also the tobacco-control NGOs who played a key role in that implementation. In addition to their relationship with Australian actors, Irish actors also created a transfer pathway with the UK, which we have termed horizontalconcurrent policy learning. As the UK was exploring the possibility of SP at the same time as Ireland, there were exchanges of information and important crossover points between the policy processes. The far larger political community and resource base in the UK meant that both sides in the Irish debate (TTCs and tobacco-control NGOs) drew on the resources available there in an attempt to influence the domestic policy process. Again, these transfer relationships not only facilitated discussion and knowledge exchange about how to develop the policy, they were also used to share knowledge on how to combat the activities of the TTCs so as to see the policy through to successful implementation.

\section{Transnational Corporations as Strategic Actors}

As discussed previously, Ireland was known to be a 'leader' in tobacco control, having led the charge in Europe for smoke-free public spaces in 2004, and had also been influential in the fight for the revision of the TPD in the EU. Its previous role as a policy 'exporter' was a particular threat to the TTCs, who feared 'policy contagion' within the EU, and pursued a coordinated, multi-faceted strategy to prevent the implementation of SP in Ireland. The political and economic context in Ireland at the time of the SP debates (see Chapter 4) was a key structural factor, which offered TTCs 
new avenues and opportunities to seek to influence the Irish government at a time of great vulnerability. The post- 2008 economic crisis faced by Ireland increased the TTCs' capacity for economic coercion, and Ireland's integration in the global economy, including its dependence on foreign direct investment (FDI) from the US, offered additional 'points of attack' and channels of engagement with the Irish government. The close relationships that TTCs maintained with important political actors and institutions in the US - for example congressional representatives from tobaccogrowing states - offered a bilateral channel of influence. The TTCs' longstanding strategy of attempting to frame tobacco control debates in terms of economic considerations and intellectual property (IP) rights, versus health (Savell et al. 2014; MacKenzie et al. 2018), was particularly pertinent in the context of the economic crisis. Similarly, Ireland's membership of the EU, and its reliance on EU economic assistance following the crisis, offered supranational channels of influence which TTCs sought to exploit, by encouraging supportive member states and other actors within EU institutions (e.g. economic and trade-focused DGs within the Commission) to exert political pressure on Ireland.

In addition to reframing the debate as one of economic consequences and IP, they promoted the idea that SP would lead to increased illicit trade and would damage the high street in an attempt to counter the public health arguments of tobacco-control actors, precisely as they had done in Australia. In terms of Evans and Davies' (1999) model of policy transfer, TTCs targeted every stage of the transfer process between Ireland and Australia (see Chapter 2). Within these stages, transfer agents were identified, and information feeder networks and transfer networks were built. Within this process, evidence from Australia was garnered, shared, evaluated and mobilised by tobacco-control advocates and policy-makers, while TTCs sought to undermine this evidence and the agents that provided it.

Working to the TTCs' advantage was the fact that SP had only very recently been enacted in Australia, so there was limited evidence emerging from that country that could affirm the policy's efficacy as a tobacco-control measure. TTCs, therefore, attempted to challenge the evidence from Australia provided by the transfer network and cited by policy advocates in support of the measures in Ireland. Furthermore, the limited evidence base allowed the industry to make unsubstantiated claims about the lack of effectiveness and the adverse consequences of the policy (e.g. increased illicit trade). The TTCs, therefore, developed their own transfer relationships 
between Australia and Ireland at this point, creating an alternative 'evidence' base to challenge SP and shipping in pro-tobacco advocates from Australia in order to disparage the policy through media and policy channels.

The final tactic that the TTCs used to disrupt the transfer of SP and contain the policy 'contagion' were legal challenges. This started with threats of legal action to the Irish government early in the policy process, which again drew parallels with the on-going experience of the Australian government. Letters were sent by TTCs to the Irish government outlining their intent to oppose the policy through the courts, and emphasising the potential consequences to an already struggling Irish economy.

The policy transfer literature does not focus explicitly on the consequences of legal challenges on the policy transfer process, although it does draw on Kingdon's (1984) work on agenda setting to address more general considerations about the political feasibility of the transfer of particular policies from one jurisdiction to another. SP already had political feasibility in Ireland; there was a high degree of public support for the policy. The tactics of the TTCs, however, shifted the venue in which the success or otherwise of the policy would be determined from the political sphere to the legal sphere. This points to an aspect of the policy process that has been under-analysed within the policy transfer literature; the potential ability to block or delay the actual implementation of the policy through its contestation by non-state actors.

This chapter and the analysis presented above demonstrate the potential for the wielding of coercive power by transnational corporations; various forms of legal redress provide important mechanisms for the realisation of this coercive power. The potential for concurrent legal challenges at multiple levels, through both domestic courts and through supranational channels via the WTO, BITs or the EU legal architecture presented myriad opportunities for TTCs to employ this coercive power, as both the Australian and European experience of SP demonstrates (Hawkins and Holden 2016; Hawkins et al. 2018). In the Irish context specifically, JTI began proceedings in the Irish commercial courts, arguing that as an EU member state Ireland could not unilaterally impose SP, as it went beyond the stipulations of the TPD and ran counter to EU single-market law. The substantive points of law were decided in a parallel case referred to the CJEU via the English courts and the industry's action failed.

The TTCs' tactics presented a potentially significant problem for policymakers and advocates in Ireland. This highlights a gap in the policy transfer 
literature, relating to the potential for non-state actors to contest policy and attempt to disrupt the transfer process to prevent policy 'contagion'. The existing literature engages with the role of non-state actors within the policy transfer process, but focuses largely on their role as transfer facilitators; civil society actors coalescing around a policy idea and knowledge base. Dolowitz and Marsh (1996) identified this group as including political consultants, but this was broadened by Dunlop (2009) and Stone (2004, 2012 ) to include a wider array of actors such as NGOs, think tanks and philanthropic organisations. Corporate actors are considered in passing within these studies in terms of their relationship to these other actors; for example, Hudson and Lowe (2009) identify how corporate actors use organisations such as think tanks to forward their agendas. Corporations are also mentioned in 'opposition' to policies in situations where policy advocates (who remain the analytical focus) have coalesced against them (Hudson and Lowe 2009). However, in these analyses, the impact of the corporation on the transfer process is not considered as a primary analytical focus.

Against this, the analysis in the current volume suggests that corporate actors can be a key influence on policy-making and, therefore, policy transfer processes. In cases such as tobacco packaging, in which the commercial interests of powerful transnational corporations are threatened by proposed regulations, corporate actors pro-actively seek to challenge and undermine the transfer process to prevent policy 'contagion' from one domain to another. This is a logical extension of wider corporate political strategies, which seek to secure political outcomes favourable to their interests. A bias in the literature towards successful instances of transfer may be an important factor in explaining the under-representation of corporate actors in existing studies, in that examples where transnational corporate actors have been successful in disrupting policy transfer may be less visible and are less amenable to study, in the same way that policy stasis, or the absence of policy change, more generally proves elusive to study. This point becomes clearer in light of Dolowitz and Marsh's (1996, 2000) framework for the analysis of policy transfer and, more specifically, their analysis of factors which restrict or facilitate policy transfer processes, and the ways in which the process of policy transfer is related to policy 'success' or policy 'failure' (see Chapter 2). Dolowitz and Marsh's (1996, 2000) responses to these questions focus on issues of policy complexity, institutional context and information deficits; the fact that actors may enter the transfer process with the explicit objective of preventing the policy transfer to protect their own interests is not considered within this framework. 


\section{The Evolution of Policy Learning Between Ireland, Australia and the UK}

The policy transfer relationship between Australia and Ireland, facilitated through transnational NGO networks, did not end with the entry of SP onto the policy agenda in Dublin. Tobacco-control advocates in Ireland also turned to Australia for ideas, advice and expertise throughout the policy process, including on the ways in which they could support the adoption and implementation of the policy in the face of TTC opposition throughout the legislative and implementation processes. As the interviews demonstrate, this changed the nature and the context of the policy transfer process itself; the TTCs changed the actions of the agents involved in the process and the relationship between them. The original transfer agents and contributors to what Evans and Davies (1999) term the 'information feeder network' were Australian tobacco-control NGOs. However, these tobacco-control NGOs were also, in Evans and Davies' (1999) terms, acting as not only the transfer agents, but also the information network and the knowledge network. The work of Diane Stone $(2004,2012)$ on non-state actors, and specifically NGOs, is also pertinent here, since the 'transnationalisation' of policy through non-state actors is again evident. Australian NGOs and policy-makers shared their experience and knowledge with Irish policy-makers and NGOs who were working in an advocacy capacity. These NGOs therefore became the 'epistemic community' for strategies related to policy adoption and implementation (as opposed to the initial idea) and the line was blurred between those acting in a 'knowledge' capacity and an 'advocacy' capacity.

As we have seen, the role soon evolved into one that included sharing information and advice on how to protect the policy from industry attack. The 'knowledge network' gave prior warnings as to what the TTCs may do, and what arguments they may deploy, to contest the policy, and shared advice and experience on how to pre-empt, react and respond to the TTCs' tactics and issue framings, including advising the Irish policy community how to use the media to support the policy. These strategies ensured that the information and evidence provided by the knowledge network, limited as it was, was able to overcome the counter-narratives and alternative 'evidence' being promoted by the TTCs. The role of the 'information feeder network' was therefore highly politicised, and much broader than the role presented in much of the policy transfer literature; it addressed not only 
the content of the policy, but also how to protect the policy from those seeking to derail it.

These protection strategies in turn altered the make-up of the advocacy network itself. The TTCs had gone to some lengths to reframe the debate about SP in terms of IP rights, arguing that SP constituted illegal expropriation of their trademarks by the government without compensation. In order to counter this argument, Australian NGOs advised Irish policy-makers and NGOs to broaden the advocacy network of the tobaccocontrol actors to include advocates from other sectors and to reframe the 'policy image' to include the wider implications of the policy, such as the impact on children. In so doing, policy advocates directly challenged the TTCs' IP rights argument with a rights-based argument of their own. The transfer agents therefore deliberately expanded the advocacy network to include representatives from other lobbies, such as children's societies, in order to develop and build a broader argument, that went beyond the remit of public health, with which to counter the TTCs' narrative. It is important to reiterate that the benefits of policy transfer were not unidirectional, however. The Australian tobacco-control community was keen to support Ireland and the UK in their efforts to implement SP, as their own policy was under attack and the external validation of their policy entrepreneurship, in the form of other countries adopting the policy, would support policy advocates' own efforts to counter TTCs' attempts to undermine and repeal the measure at home. The policy transfer process was therefore used not only as a mechanism to inform colleagues in a new policy setting about the prior experiences of other jurisdictions, it was intentionally developed to ensure the success of the policy in both jurisdictions.

This case of SP in Europe therefore offers several new insights into the policy transfer process, particularly with regard to the role of transnational corporate actors who seek to not only become involved in the transfer process, but to disrupt and undermine it, and to use transfer mechanisms themselves for this purpose. Revisiting Dolowitz and Marsh's (1996) heuristic framework helps emphasise this point, as the questions they forward to establish policy transfer mechanisms reveal several analytical insights not as yet discussed in the literature:

1. Who are the key actors involved in the policy transfer process? Although transnational corporations are sometimes mentioned in this regard, the literature tends to focus on the most common agents of policy transfer-elected officials, policy entrepreneurs or experts, political 
parties, bureaucrats, advocacy groups and supranational institutions (Dolowitz and Marsh 1996, 2000; Evans 2009). The case analysed in this volume has demonstrated that this question, however, raises another pertinent question-who seeks to prevent policy transfer? Transnational corporate actors not only can use transfer mechanisms themselves to forward their own political agendas, but may actively seek to disrupt the transfer processes of other actors. Furthermore, they hold some coercive power, through their economic importance in some countries, through their well-organised political agency and through their ability to exploit legal mechanisms, particularly those at the supranational level. They can therefore be significant actors in the transfer process, in ways not well investigated so far in the literature.

2. Why engage in policy transfer? Dolowitz and Marsh (1996, 2000) framed policy transfer in terms of voluntary and coercive mechanisms, the latter being what differentiated it from 'lesson-drawing'. They argued that policy transfer came about inter alia through the dissatisfaction of policy-makers, public unhappiness, perceived policy failure, and uncertainty. This case demonstrates however that a key explanatory factor that consolidated the transfer pathways and their associated networks between Ireland, Australia and the UK was the need to counteract the activities of the TTCs. Relationships between pro-public health policy-makers and NGOs were forged and strengthened in part in order to share tactics and form a coalition that resisted TTCs' strategy of trying to block, amend or delay the policy.

3. What elements of policy are transferred? Dolowitz and Marsh (1996, 2000) listed a number of 'hard' policy instruments such as policy goals, policy instruments, institutions and programmes, which others such as Stone $(2004,2012)$ expanded to include 'softer' elements of policy, such as ideas, ideologies and concepts. In this case we can see that although policy ideas, goals and instruments were transferred, as important were political strategies and tactics to ensure that the policy was adopted and carried through to implementation.

4. From where are policies transferred? The traditional transfer literature focused predominantly on bilateral transfer between national governments (e.g. Jones and Newburn 2006). As the theory evolved, the 'internationalisation' of the theory saw more of a preoccupation with forces such as globalisation, Europeanisation and multi-level governance, which studied vertical pathways of transfer as well as horizontal pathways. This case importantly demonstrates that one policy had 
multiple different potential transfer pathways, which could be concurrent as well as consecutive; SP was blocked at the EU level, but strengthened packaging requirements were nevertheless transferred vertically from the EU's supranational level to set a floor for member states, with the TPD specifically allowing action on SP at the national level; at the same time, several horizontal pathways emerged between Ireland, Australia and the UK to address the implementation of the policy and to counteract the TTCs' contestation. This suggests that for analytical rigour, it is necessary to break down policies into 'component parts' in order to understand the transfer and diffusion of policies in an increasingly globalised world, and to take particular account of the different possible pathways within multi-level systems of governance.

5. What factors enable and constrain transfer? The traditional literature focuses on policy complexity as the main constraint to transfer, arguing that policy complexity and embeddedness in wider social and political contexts can impede transfer from one jurisdiction to another (Dolowitz and Marsh 1996, 2000; Evans 2009). The increase in nonstate actors and multi-level governance structures through increased globalisation has the potential to uncover further constraints, which Benson and Jordan (2011) argue have not yet been analysed sufficiently in the literature. What is not mentioned, importantly, is deliberate contestation of the policy and its transfer. With the omission of transnational corporate actors from the analysis, and the bias in the empirical literature towards 'successful' instances of transfer, an important transfer constraint can be overlooked, i.e. the presence of actors actively trying to prevent transfer-or 'contagion'-occurring when a policy idea goes against their interests.

\section{CONCLUSION}

By applying policy transfer theory to the development of standardised packaging policy, this volume has demonstrated that transnational corporate actors can have a significant impact on the transfer potential and efficacy of public health policies. Three theoretical conclusions can be drawn from this case. The first refers both to the transit of the policy idea itself and to the development of the tactics needed to ensure its adoption. In a globalised 
world, the potential pathways of transfer are multiple and may be concurrent as well as consecutive. This is particularly true in multi-level polities such as the EU. Furthermore, networks of policy actors engaged in the exchange of ideas, knowledge and tactics may be crucial to the successful adoption of the policy within such multi-level systems. We can conclude, therefore, that the increase in multi-level governance structures creates a complex matrix which transfer networks must navigate, creating policy transfer 'webs' that differ from the bilateral modes of transfer studied in much of the literature.

The second theoretical conclusion relates to the role of transnational corporate actors. Such actors have in general been neglected in the literature, other than as indirect sponsors of think tank research in policy areas where they have a business interest (Hudson and Lowe 2009). While there is certainly evidence of this in this study, a much more direct link to the transfer process is also apparent. We see here that TTCs were directly concerned with policy transfer - or from their perspective policy 'contagion'. Consequently, their strategies were built around preventing transfer, with some level of success, as seen in their activities surrounding the TPD. Furthermore, these transnational corporate actors have coercive power-their economic weight and political sophistication mean that they can apply pressure both directly and through enlisting other nation states to apply pressure on their behalf. The complex supranational legal architecture of institutions such as the WTO and the EU also provides them several points of potential coercion through legal threats and actions. Additionally, transnational corporate actors may not only seek to disrupt the transfer process, they can also create their own transfer pathways-in this case, mirroring the transfer relationship between Irish and Australian NGOs to transport members of their own epistemic network (which supports the counter-idea of the negative impacts of SP) from Australia to Ireland.

This integration of transnational corporate actors within the policy transfer process has several analytical consequences. Their omission from the literature means that a significant global source of power is missing from current theory. The consequences of their activities include the disruption or prevention of transfer, which may result in transfer failure-an important aspect of analysis, as Dolowitz and Marsh's (1996, 2000) heuristic framework demonstrates. Their activities could also be a cause of variations in the implementation of policies, or the timing of their adoption, which may also be influenced by structural factors such as a country's perceived economic 
reliance on an industry, or historical factors that facilitate or constrain an industry's coercive power.

Another consequence of transnational corporate actors' activities within the transfer process relates to our third theoretical conclusion, which addresses the transfer pathways that emerged in response to TTCs' activities. While there is some policy transfer literature that refers to the exchange of political tactics (e.g. Pierson and Castles 2002), this example differs from this sub-literature in two ways. The first is that, in this example, the tactical exchange is not about defeating domestic political opponents; rather, it is about how to combat policy opponents that are active across jurisdictions in trying to prevent the transfer process. Second, the transfer pathways of policy-maker and NGO networks became part of a political strategy to secure the success of the policy. Australian advocates deliberately shared their experience with Ireland and the UK not only to help them in their battle with the TTCs, but also because having the policy implemented in other jurisdictions worked to Australian actors' advantage, as the diffusion of the policy offered validation of the policy's efficacy. Various ideas proliferate in the literature as to why policy transfer occurs; constructivist diffusion theorists point to changes in ideas and the influence of global norms (e.g. Meyer et al. 1992), while coercion theorists point to power dynamics and changes in incentives (Owen 2002). In the transfer school, Dolowitz and Marsh $(1996,2000)$ point to reasons such as dissatisfaction among policy-makers or the public, perceived policy failures, or uncertainty. What we see in this case, however, is that transfer occurred in part due to a political decision to enable diffusion, in order to validate policy choices in both the 'exporter' and 'importer' jurisdictions. Where the transfer process is highly politicised, therefore, it could be inferred that this could speed up diffusion or transfer, as policy advocates seek to spread the idea as far as possible. Indeed, in this case, the very nature of the transfer process itself was determined in part by the need for policy-makers and NGOs to build relationships and coalitions in an effort to counteract transnational corporate actors' strategies in both the 'exporting' and 'importing' jurisdictions.

This volume has both provided new empirical data on the battle for standardised packaging in Europe and contributed new theoretical insights on the nature of policy transfer processes in multi-level polities. It has shown how the combination of complex, multi-level governance systems with networks of policy-makers and NGOs may give rise to policy transfer 'webs', potentially containing multiple consecutive and/or concurrent processes 
of both 'horizontal' and 'vertical' policy exchange. It has further demonstrated that a closer analytical look at the roles of transnational corporate actors is necessary within the policy transfer literature. We have demonstrated that TTCs not only sought to attack and disrupt transfer mechanisms that were facilitating the adoption of SP, but that they also developed their own 'counter-policy' transfer pathways. The impact on the success of the policy transfer process was mixed; while the TTCs achieved some success at the EU level, and induced a 'chilling effect' in some jurisdictions that delayed adopting the policy at the national level, in other ways the activities of the TTCs inadvertently encouraged the development of networks committed to the successful diffusion of the policy.

\section{BIBLIOGRAPHY}

Baumgartner, F., \& Jones, B. (1991). Agenda dynamics and policy subsystems. The Journal of Politics, 53(4), 1044-1074.

Benson, D., \& Jordan, A. (2011). What have we learned from policy transfer research? Dolowitz and Marsh revisited. Political Studies Review, 9(3), 366378.

Bomberg, E., \& Peterson, J. (2000). Policy transfer and Europeanization: Passing the Heineken Test? (Queen's Papers on Europeanisation p0002). Queen's University Belfast.

Chapman, S., \& Freeman, B. (2014). Removing the emperor's clothes: Australia and tobacco plain packaging. Sydney: Sydney University Press.

Costa, H., Gilmore, A. B., Peeters, S., McKee, M., \& Stuckler, D. (2014). Quantifying the influence of the tobacco industry on EU governance: Automated content analysis of the EU Tobacco Products Directive. Tobacco Control, 23, $473-478$.

Dobbin, F., Simmons, B., \& Garrett, G. (2007). The global diffusion of public policies: Social construction, coercion, competition, or learning? Annual Review of Sociology, 33, 449-472.

Dolowitz, D. (2003). A policy-maker's guide to policy transfer. The Political Quarterly, 74(1), 101-108.

Dolowitz, D., \& Marsh, D. (1996). Who learns what from whom: A review of the policy transfer literature. Political Studies, 44(2), 343-357.

Dolowitz, D., \& Marsh, D. (2000). Learning from Abroad: The role of policy transfer in contemporary policy-making. Governance, 13(1), 5-23.

Dunlop, C. A. (2009). Policy transfer as learning: Capturing variation in what decision-makers learn from epistemic communities. Policy Studies, 30(3), 289311. 
Evans, M. (2009). Policy transfer in critical perspective. Policy Studies, 30(3), 243268.

Evans, M., \& Davies, J. (1999). Understanding policy transfer: A multi-level, multidisciplinary perspective. Public Administration, 77(2), 361-385.

Gleditsch, K. S., \& Ward, M. D. (2006). Diffusion and the spread of democratic institutions. International Organisations, 60, 911-933.

Hawkins, B., \& Holden, C. (2016). A corporate veto on health policy? Global constitutionalism and investor-state dispute settlement. Journal of Health Politics, Policy and Law, 13, 1-19.

Hawkins, B., Holden, C., \& Mackinder, S. (2018). A multi-level, multijurisdictional strategy: Transnational tobacco companies' attempts to obstruct tobacco packaging restrictions. Global Public Health. https://doi.org/10. 1080/17441692.2018.1446997.

Holden, C., \& Hawkins, B. (2017). Law, market building and public health in the European Union. Global Social Policy, 1-17.

Holden, C., \& Lee, K. (2009). Corporate power and social policy: The political economy of the transnational tobacco companies. Global Social Policy, 9(3), 328-354.

Hudson, J., \& Lowe, S. (2009). Understanding the policy process: Analysing welfare policy and practice (2nd ed.). Bristol: Policy Press.

Hurt, R. D., Ebbert, J. O., Muggli, M. E., Lockhart, N. J., \& Robertson, C. R. (2009). Open doorway to truth: Legacy of the Minnesota tobacco trial. Mayo Clinic Proceedings, 84(5), 446-456.

Jarman, H. (2015). The politics of trade and tobacco control. Basingstoke: Palgrave Macmillan.

Jones, T., \& Newburn, T. (2006). Policy transfer and criminal justice. Milton Keynes: Open University Press.

Jordan, A., Wurzel, R., Zito, A. R., \& Brückner, L. (2003). European governance and the transfer of 'new' environmental policy instruments (NEPIs) in the European Union. Public Administration, 81(3), 555-574.

Kingdon, J. W. (1984). Agendas, alternatives and public policies. Boston, MA: Little, Brown.

MacKenzie, R., Mathers, A., Hawkins, B., Eckhardt, J., \& Smith, J. (2018). The tobacco industry's challenge to standardised packaging: A comparative analysis of issue framing in public relations campaigns in four countries. Health Policy, 122(9), 1001-1011.

Meyer, J. W., Ramirez, F. O., \& Soysal, Y. (1992). World expansion of mass education, 1870-1980. Sociological Education, 65, 128-149.

Owen, J. M. J. (2002). The foreign imposition of domestic institutions. International Organizations, 56, 375-409.

Peeters, S., Costa, H., Stuckler, D., McKee, M., \& Gilmore, A. B. (2015). The revision of the 2014 European Tobacco Products Directive: An analysis of the 
tobacco industry's attempts to 'break the health silo'. Tobacco Control. https:// doi.org/10.1136/tobaccocontrol-2014-051919.

Pierson, C., \& Castles, F. G. (2002). Australian antecedents of the Third Way. Political Studies, 50, 683-702.

Radaelli, C. (2000). Policy transfer in the European Union: Institutional isomorphism as a source of legitimacy. Governance, 13(1), 25-43.

Savell, E., Gilmore, A. B., Fooks, G., \& Derrick, G. E. (2014). How does the tobacco industry attempt to influence marketing regulations? A systematic review. PLoS One, 9, e87389. https://doi.org/10.1371/journal.pone. 0087389.

Smith, K. E., Savell, E., \& Gilmore, A. B. (2013). What is known about tobacco industry efforts to influence tobacco tax? A systematic review of empirical studies. Tobacco Control, 22(2), 144-153.

Stone, D. (2004). Transfer agents and global networks in the 'transnationalization' of policy. Journal of European Public Policy, 11(3), 545-566.

Stone, D. (2012). Transfer and translation of policy. Policy Studies, 33(6), 483-499.

World Health Organization (WHO). (2003). WHO framework convention on tobacco control [Online]. Available at https://www.who.int/tobacco/ framework/WHO_FCTC_english.pdf. Accessed 5 February 2019. 